\title{
A INOVAÇÃO SOB A ÓTICA DO DESIGN SUSTENTÁVEL: UMA REVISÃO DA LITERATURA.
}

\section{THE INNOVATION FROM THE PERSPECTIVE OF SUSTAINABLE DESIGN: A LITERATURE REVIEW.}

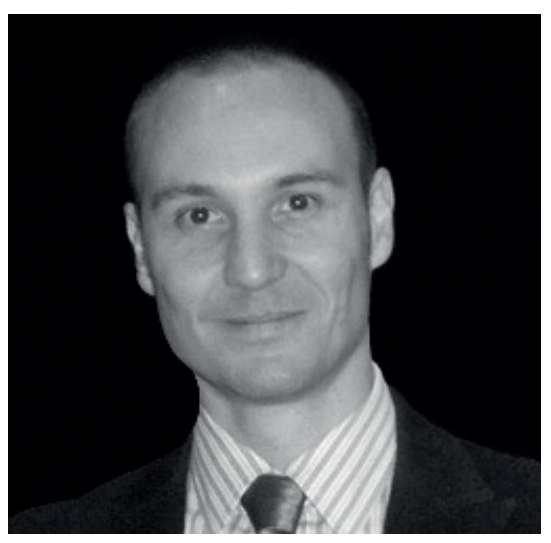

\section{André de Souza Lucca}

Doutor em Ciências do Design, Università IUAV di Venezia - Itália

Curso de Ciência e Tecnologia, Universidade Federal do Maranhão

aslucca@yahoo.com.br

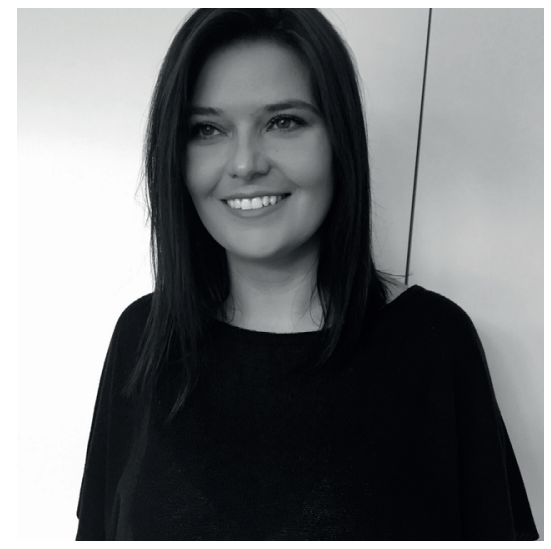

\section{Carolina Daros}

Mestre em Design, Universidade Federal do Paraná

Programa de Pós-graduação em Design, Universidade Federal do Paraná

carolinadaros@gmail.com 


\section{RESUMO}

Baseado em uma revisão bibliográfica narrativa, o presente texto apresenta as relações entre ciência, tecnologia e projeto buscando entender os princípios da inovação sob a ótica do Design. O objetivo é contribuir para o entendimento das implicações do conceito de inovação no desenvolvimento de produtos e serviços sustentáveis. O pressuposto é que a inovação científica e a inovação pelo Design convergem para alimentar as dinâmicas econômicas. Enquanto que a inovação científica representa um ingrediente indispensável na busca pela competitividade econômica, o Design se transforma no campo ideal para o desenvolvimento de inovações sustentáveis. Este estudo permitiu inferir que a inovação pelo Design acontece quando o projeto é capaz de alcançar resultados que proporcionam o aparecimento de novos modelos de comportamento, o estabelecimento de resultados econômicos para os produtores e de modificações no contexto social.

\section{PALAVRAS-CHAVE}

Inovação; Desenvolvimento de Produtos e Serviços; Sustentabilidade.

\section{ABSTRACT}

Based on a narrative bibliographic review, this text presents the relationships between science, technology and design as an attempt to understand the principles of the innovation from the perspective of industrial design. The objective is to contribute to the understanding of the implications of the concept of innovation in the development of sustainable products and services. The assumptions of this work is that the scientific restructuring and the innovation of design converge to increase the economic dynamics. While the scientific innovation represents an essential ingredient in the search for economic competitiveness, the design becomes the ideal field for the development of sustainable innovations. This study allowed us to infer that the design innovation happens when the project is able to produce results that make possible new models of behavior, the establishment of economic results for the producers, and also real changes in the social context.

\section{KEYWORDS}

Innovation; Development of Products and Services; Sustainability. 


\section{INTRODUÇÃO}

O debate sobre as implicações da inovação no desenvolvimento econômico surgiu a partir dos estudos de Schumpeter em seu texto Teoria do Desenvolvimento Econômico, publicado no princípio do século XX. Nessa obra, o autor definiu os conceitos de inovação e invenção, evidenciando as diferenças existentes entre estes dois princípios.

Para Schumpeter (1971) a invenção é uma ideia genial que inicialmente nasce sem fins comerciais. Então, inventar significa conceber pela primeira vez uma ideia. Inovar, por sua vez, é a tentativa de colocar em prática essa nova ideia. É a introdução no mercado de uma invenção.

Deste modo, a inovação é realizada principalmente por empresas e apresenta uma forte pertinência econômica. Pode ocorrer também que algumas invenções jamais se traduzam em inovações, por falta de conhecimentos adequados, inputs ou outros fatores complementares. Para transformar uma invenção em inovação os agentes econômicos devem ser capazes de combinar diversos tipos de conhecimentos, capacidades, competências e recursos (SCHUMPETER, 1971).

Neste sentido, Schumpeter (1971) considera que a inovação pode ser promovida como a introdução de novas combinações em um sistema produtivo e pode acontecer num dos seguintes casos:

na produção de um novo bem ou de uma nova qualidade, através da introdução de um novo produto, serviço ou sistema inédito aos consumidores ou de uma nova característica, mesmo que o bem já exista;

na introdução de um novo método de produção, por meio da introdução de um novo processo;

na abertura de um novo mercado para a introdução de um produto, mesmo que esse produto ou esse mercado já existam;

na conquista de uma nova fonte de aprovisionamento de matérias-primas ou de bens semimanufaturados, independente dessa fonte existir, ser descoberta ou criada;

na reorganização de uma atividade produtiva, como no estabelecimento de novas estratégias ou de novos processos.

Porém, segundo Schumpeter (1971), a inovação representa só um componente do mecanismo econômico sendo a competição tecnológica, alcançável através da inovação, a real força motriz do desenvolvimento econômico. Quando uma empresa introduz com sucesso uma inovação no mercado, ela será amplamente recompensada e imitada pelas demais empresas que buscarão compartilhar os 
benefícios alcançados, ocasionando a diminuição das vantagens obtidas pela primeira empresa inovadora. Para Schumpeter (1971) o acúmulo de imitadores provoca o crescimento do setor por um determinado tempo, porém, cedo ou tarde os efeitos diminuem e o crescimento cessa.

A partir do estudo de sua obra, Vertova (2009) sustenta que Schumpeter não se interessava na análise específica de uma inovação, mas sim, nos conjuntos de inovação denominados clusters. Para o autor são os clusters que, conectados entre si, criam o impulso para o crescimento durável e o desenvolvimento tecnológico. Por isso, Schumpeter (1999) afirma que cada mudança tecnológica é movida por forças de destruição e criação, evidenciando o fato de que cada alteração na estrutura econômica produz novos elementos e elimina os antigos.

Neste sentido, Marinova (2009) corrobora a ideia de que as mudanças tecnológicas estão sujeitas a uma tendência de domínio de alguns tipos de tecnologia sobre as demais e sugere que esse fenômeno possibilita o surgimento de ondas de inovação, conforme a Figura 1.

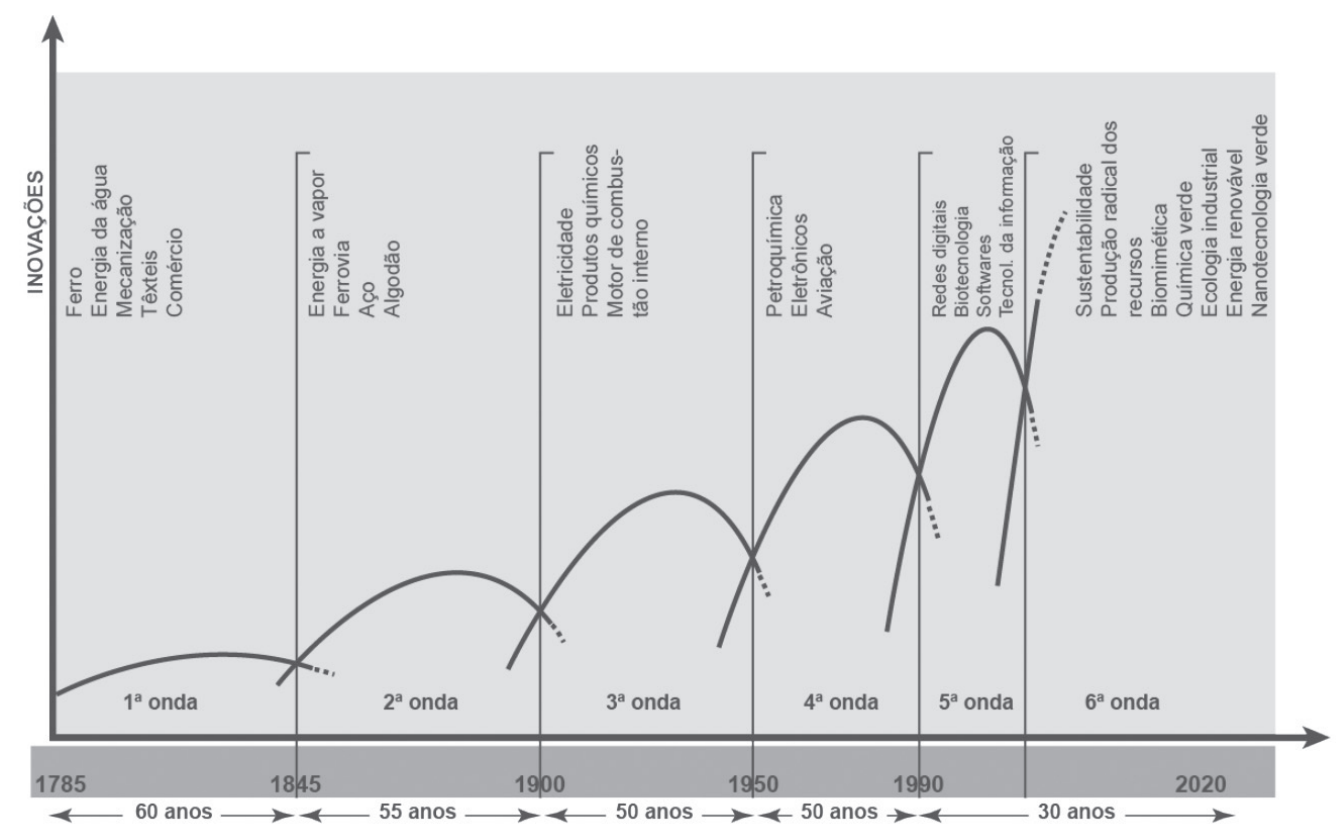

Figura 1: Ondas de inovação. Fonte: Daros (2013) adaptado Hargroves e Smith (2005, p. 17)

Segundo Marinova (2009) as ondas de inovação mostram que as novas tecnologias são orientadas para a solução dos problemas que anteriormente eram considerados de difícil resolução e que, por consequência, originam a busca 
por novos métodos de produção, novas estruturas socioinstitucionais, políticas e econômicas na sociedade.

Para Marinova (2009) a quinta onda ainda é muito atuante na sociedade atual e está associada ao desenvolvimento e a utilização de tecnologias da informação, sendo a internet a melhor manifestação para a difusão dessas tecnologias. Contudo, em muitos aspectos a sociedade contemporânea já demonstra estar em processo de transição para uma nova onda. A sexta onda emerge com a característica de promover tecnologias voltadas para a sustentabilidade e a resiliência do ambiente e torna visível a necessidade alterar os meios de produção e promover novos estilos de vida para as próximas gerações.

Ainda segundo Marinova (2009) as ondas de inovação anteriores buscavam no desenvolvimento tecnológico a melhoria da qualidade de vida do ser humano, considerando as imposições do mercado e a busca pelo benefício máximo. Já o atual o interesse pelas tecnologias orientadas para a sustentabilidade está apoiado na crença de que essas tecnologias desempenharão exatamente a função de desvincular o crescimento econômico da degradação ambiental, ainda que a Organização para a Cooperação e Desenvolvimento Econômico (OECD, 2000; 2002) evidencie a limitação dessa proposição, baseando-se no fato de que é difícil assegurar que as inovações ocorram onde e quando são mais necessárias ou a um preço que reflita os benefícios ambientais e sociais de sua aplicação.

Por esse motivo, torna-se relevante um exame mais aprofundado sobre as implicações do uso estratégico do conceito de inovação no desenvolvimento de produtos e serviços baseados em tecnologias voltadas para a sustentabilidade. Assim, na sequência deste trabalho serão apresentadas e discutidas as relações entre a inovação e as principais abordagens de design para o desenvolvimento de produtos e serviços sustentáveis.

\section{METODOLOGIA}

A pesquisa que gerou o presente trabalho empregou o levantamento bibliográfico narrativo como instrumento para coleta de dados. Essa abordagem permitiu entender como o conceito de inovação foi incorporado no Design a partir das áreas da Economia e da Ciência, bem como, forneceu o embasamento necessário para a compreensão do significado da inovação sob a ótica do Design sustentável.

Segundo Rocha (1999 apud VOSGERAU; ROMANOWSKI, 2014) o levantamento bibliográfico narrativo é um estudo que tem por característica permitir o esta- 
belecimento de relações com produções bibliográficas anteriores, identificando temáticas recorrentes e apontando novas perspectivas.

Para o desenvolvimento desta pesquisa foram selecionadas obras bibliográficas e estudos acadêmicos de autores proeminentes na área do Design, Economia e Ciência que tratam, particularmente, da inovação e de suas relações com a sociedade e a tecnologia.

\section{DESENVOLVIMENTO}

\subsection{A INOVAÇÃO NA CIÊNCIA E NO PROJETO}

De acordo com Kuhn (1978) na pesquisa científica a inovação é entendida como um processo de construção do conhecimento. $O$ conhecimento é constituído pela observação de dados através de procedimentos do tipo indutivo-hipotético-dedutivo. Tais observações levam a construção de formulações teóricas que estabelecem uma sistematização coerente e projetam ligações plausíveis com outras formulações teóricas, postulando aspectos não diretamente observáveis, dos quais descendem as hipóteses de pesquisa que darão vida para novas investigações e teses, confirmáveis ou contestáveis. Chega-se, assim, a formulação de novas teorias científicas que se caracterizam por serem panorâmicas, organizativas e explicativas dos fenômenos observados. Essas teorias guiam a pesquisa, permitem a colocação dos dados numa trama articulada, dando a elas um significado que, de outro modo, não possuiriam, ajudam a desenvolver as hipóteses, que serão depois submetidas a verificação e, por fim, orientam a escolha do método mais apropriado para testá-las. Portanto, a atividade científica fundamenta suas bases no conceito de inovação. A inovação representa o motor do progresso científico que possibilita a contínua evolução com o qual a ciência está sujeita por sua própria natureza. Isso permite o acesso aos novos saberes que incrementam a bagagem de conhecimentos do homem. Por isso, a inovação científica é entendida como descoberta, revelação daquilo que já existe, mas que se esconde no universo, um esforço do pensamento para revelar as formas da natureza.

A investigação científica é um procedimento experimental enquanto analisa as relações existentes entre os fenômenos em condições protegidas e replicáveis de laboratório. Não se trata de uma observação livre de eventos que acontecem espontaneamente na natureza. Geralmente são os cientistas que fazem interagir artificialmente as variáveis para a posterior definição das suas relações.

Além disso, o espaço no qual se move o pesquisador é a comunidade científica, entendida como o inteiro grupo de cientistas, das suas relações e interações. 
Nesse espaço, a objetividade deve ser alcançada com o emprego do método científico e com o debate ao interno da comunidade científica.

Na opinião de Bonsiepe (2004) as atividades científicas e as atividades projetuais se distinguem por terem distintos interesses. Contudo, ambas compartilham de uma mesma realidade. Enquanto que o projetista observa o mundo do ponto de vista da planificação, o cientista observa o mundo através da perspectiva da reconhecibilidade. São dois conceitos diferentes, como também são diversos os resultados frente ao processo de inovação. Se o cientista produz novos conhecimentos, o projetista produz, ou permite que aconteçam novas experiências de uso dos produtos, dos serviços e dos signos, ou seja, ele se move ao interno do cotidiano das pessoas.

Apesar das diferenças acima enunciadas, ambas atividades convergem para alimentar as dinâmicas econômicas. Enquanto que a inovação científica, sempre mais estimulada pelo mercado em razão da sua capacidade de se transformar em inovação tecnológica, representa um ingrediente indispensável na busca pela competitividade econômica, a atividade projetual, devido a sua competência no âmbito técnico-produtivo e a sua capacidade de dialogar com o inteiro tecido social, se transforma no campo ideal para o desenvolvimento de inovações sociais (BONSIEPE, 2004).

Então, a inovação pelo Design pode ser entendida como o resultado de uma dinâmica social, na qual as necessidades percebidas pelas pessoas, pela economia e pelas instituições, são associadas com os conhecimentos gerados pela ciência, para depois retornar para a coletividade na forma de artefatos, conhecimentos e signos. Ao considerar a própria atividade projetual, a inovação pelo Design também se refere aos processos de produção, aos graus de qualidade, às modalidades de distribuição, às formas de consumo e à própria elaboração do projeto.

Para Tamborrini (2009) a inovação pelo Design significa colocar em prática um processo de transformação que preveja a implementação da qualidade dos modos, das ferramentas, dos valores e dos objetivos da ação humana. Para o autor, isso acontece através da introdução de elementos dotados de uma novidade ontológica (diferente de ...) e não de uma novidade cronológica (mais recente...). São novos elementos ou inéditas conexões entre os elementos existentes, novos atores, novas regras, novas estratégias que num período de tempo racional sejam reconhecidas como válidas e colocadas em prática.

Penati (1999) acrescenta que a inovação também é associada com a ideia de novidade de caráter tecnológico ou estético formal e que tal equívoco é largamente explorado na promoção de produtos ou serviços. Para o autor, por sua própria 
natureza a inovação constitui um processo altamente incerto ao passo que as atividades inovadoras se desenvolvem através de caminhos previamente desconhecidos. As reais potencialidades de aplicação de um novo produto ou de um novo processo, assim como a conveniência econômica que poderá derivar do seu potencial sucesso comercial, em muitos casos, não são perceptíveis desde o princípio. Além disso, as expectativas, os interesses e os fins de quem inova não constituem uma referência cristalizada e estável no tempo. Por isso, não existe uma norma unívoca que conduza uma ação na direção da inovação que é, em geral, alcançável através de diversos métodos, alguns até contraditórios.

Para Capella (2000) a função do designer na busca pela inovação caracteriza-se pela análise e entendimento das necessidades coletivas e no suporte para que os atores econômicos busquem as soluções apropriadas, isto é, procurando escapar daquilo que Thackara define como o dilema da inovação. Em sua entrevista para Capella (2000), Thackara sugere que tal dilema está caracterizado pelo fato de que hoje as empresas sabem realizar tecnicamente produtos e serviços excepcionais, mas não sabem analisar as necessidades sociais e culturais da sociedade que estão em contínua transformação.

Thackara (2008) afirma que o dilema da inovação é um obstáculo no caminho de um mundo mais centrado nas pessoas do que nos objetos. Muitos acreditam que ser inovador significa acrescentar tecnologia mesmo quando, assim fazendo, a qualidade de vida seja reduzida. Para o autor, na maior parte da era moderna, os benefícios da tecnologia pareciam claros como a luz do sol, hoje, os supostos benefícios da tecnologia estariam em contraste com as obscenas quantidades de energia e recursos incorporados na produção, no uso e no descarte dos bens e serviços.

Thackara (2008) não considera que a sustentabilidade e a tecnologia excluem-se reciprocamente, mas alerta que o uso da tecnologia deve ser feito somente quando ela permitir uma simplificação na vida das pessoas e se ela puder ser produzida e utilizada de forma branda.

\subsection{A INOVAÇÃO PELO SIGNIFICADO}

Inovar pelo significado é uma abordagem de projeto que trata da mudança de significado dos produtos e serviços através das emoções e das relações de afeto que conectam os clientes e usuários com qualquer bem ou negócio. É um tipo de inovação que pode ser considerada como guiada pelo design. Segundo Verganti (2012) para propor novos significados para um produto é necessário uma investigação mais profunda sobre a experiência de uso que as pessoas de- 
sejam, ou podem vir a desejar, e como elas receberão e perceberão essas novas propostas. Então, esse tipo de inovação exige a verificação e o entendimento de como ocorre a evolução na vida das pessoas em termos socioculturais, estilos de vida e evolução tecnológica.

Assim, o sentido de projeto vai além do âmbito material do desenvolvimento do produto ou do serviço, mas abrange também as influências que estes imprimem nas pessoas, as reações, interações e as interpretações que podem produzir (DE MORAES, 2010).

Portanto, existe um contexto emocional, psicológico e sociocultural embutido nesse processo que depende dos valores, das crenças, das normas e das tradições (VERGANTI, 2012). Desta maneira, percebe-se que as propostas com características inovadoras pelo significado, geralmente, exigem a compreensão de problemas que, de acordo com Franzato (2010), ultrapassam os limites do Design. Por isso, o processo de inovação pelo significado demanda a participação de equipes multi e interdisciplinares, formadas por pesquisadores e especialistas nos diversos setores comprometidos com a resolução dos problemas de projeto (CELASCHI, 2008; VERGANTI, 2012).

Essas equipes apontam alternativas ou tendências a partir de exercícios de prospecção. As abordagens e processos de natureza prospectiva buscam entender quais são as forças que orientam o futuro, de modo a promover transformações, dando direção e foco para as mudanças. Por outro lado, os estudos prospectivos são conduzidos de maneira a agregar valor nas informações, transformando-as em conhecimento. Esse conhecimento pode auxiliar os decisores e os formuladores de políticas na construção de estratégias, além de identificar a direção e as oportunidades futuras para os diversos atores sociais (ZACKIEWICZ et al, 2005). Verganti (2012) acredita que associando o processo de inovação à tecnologia, ao design e ao mercado é possível reelaborar ou descobrir novos significados para os produtos e serviços. Neste caso, a inovação é uma combinação entre o avanço tecnológico (technology-push), pesquisas centradas no usuário (market-pull), pesquisas de significado (meaning-driven) que, por consequência, produzem as epifanias tecnológicas (technology epiphanies).

Para o autor, as epifanias tecnológicas são produtos ou serviços que apresentam conceitos anteriormente inexplorados, ou seja, utilizam novas tecnologias ou aplicam aquelas conhecidas em novos contextos. Assim, apresentam maior impacto sobre o contexto sociocultural e o mercado, sobrevivendo por mais tempo. Para as inovações radicais de significado, a pesquisa de design deve ser orientada para as interpretações e para o entendimento do que pode ser significativo 
para as pessoas. Segundo Celaschi e Deserti (2007 apud VIEIRA, 2007), as abordagens tradicionais do design são voltadas para os aspectos tangíveis do produto, enquanto que o contexto atual exige que se observe outras dimensões, mais intangíveis, como a comunicação e a experiência.

Além disso, os estudos semânticos no design de produtos estabelecem que todo objeto, além de sua funcionalidade prática e estética, também é um símbolo cultural que possui significados. Nesse tipo de estudo, são analisados os aspectos simbólicos dos artefatos gerados em sua fase de uso. Então, a inovação pelo significado não está necessariamente atrelada aos avanços tecnológicos, mas em grande parte às relações simbólicas de uso dos produtos por seus usuários.

\subsection{A INOVAÇÃO SUSTENTÁVEL}

Para Vezzoli e Manzini (2007) a principal característica que define o Design sustentável é que este considera o objeto do projeto como um sistema composto por produto mais serviço e comunicação. Um conjunto definido como único e denominado sistema-produto.

De acordo com Manzini e Jégou (2003) a sustentabilidade é trabalhada através de uma abordagem de projeto orientada para a busca da inovação radical. Para os autores a inovação sustentável deve guiar os processos na direção de uma mudança sistêmica, que implique uma qualquer forma de ruptura com a continuidade de uma dada situação e, na qual, o resultado esteja coerente com os critérios fundamentais da sustentabilidade. Deste modo, os autores evidenciam uma específica particularidade da inovação sustentável que, porém, nem todas as inovações possuem, isto é, aquela de condicionar radicalmente um dado sistema econômico determinando diferentes níveis de desenvolvimento. Para melhor entender esse conceito é útil rever a taxonomia proposta por Freeman e Perez (1988) na qual os autores definem a inovação com base no impacto que ela impõe sobre a economia. Segundo os autores as inovações podem ser descritas a partir de quatro grupos:

inovações incrementais: se desenvolvem não como o resultado de uma pesquisa deliberada mas como o resultado de melhoramentos sugeridos por técnicos diretamente empenhados no processo produtivo. Isso ocorre através de um processo de learning by doing e de learning by using ou como o resultado de sugestões de usuários e consumidores. Apesar de seus efeitos serem importantes para o crescimento da produtividade, as inovações incrementais não apresentam efeitos relevantes sobre o sistema econômico;

inovações radicais: são eventos descontínuos que rompem com o plano domi- 
nante e são, normalmente, o resultado de uma pesquisa intencional conduzida por empresas, universidades ou em laboratórios científicos;

mudanças de sistema tecnológico: são mais difíceis de se alcançar pois se referem às inovações que influenciam diretamente diversos aspectos da economia, fazendo surgir setores completamente novos. Tais mudanças são baseadas em uma combinação de inovações radicais e incrementais, estruturadas por inovações organizativas e gerenciais; revoluções tecnológicas: as revoluções tecnológicas trazem consigo muitos clusters de inovação radical e incremental e podem incorporar um certo número de novos sistemas tecnológicos. Uma característica vital deste quarto tipo de inovação é o seu efeito invasivo no inteiro sistema econômico. Traz consigo não somente a aparição de uma nova gama de produtos, serviços, sistemas e indústrias, mas, influencia diretamente todas as outras categorias da economia.

Assim, é compreensível que as ações necessárias para promover inovações sustentáveis devem objetivar mudanças radicais, ou seja, que promovem eventos que interrompem com os atuais comportamentos e, portanto, mais adequadas para a produção de novos comportamentos nos indivíduos e, consequentemente, na sociedade. Mas não somente isso, tais inovações devem ser flexíveis ao ponto de permitir combinações com as inovações incrementais, organizativas e gerenciais existentes e de induzir mudanças intrinsecamente sustentáveis no inteiro sistema tecnológico. Além disso, inovar sob a ótica da sustentabilidade, significa considerar um sistema em sua complexidade de sistema social, tecnológico e ambiental.

\subsection{A INOVAÇÃO SOCIAL}

Para Manzini (2008) o termo inovação social refere-se as mudanças no modo como os indivíduos ou as comunidades agem para resolver seus problemas ou criar oportunidades. Tais inovações são guiadas mais por mudanças de comportamento do que por mudanças tecnológicas ou de mercado, geralmente emergindo através de processos estruturados por uma abordagem bottom-up. Manzini (2008) considera que o conjunto da sociedade pode ser visto como um imenso laboratório de ideias para o cotidiano, onde os modos de ser e de fazer se desdobram em novas questões e respostas.

Existem casos em que essa criatividade socialmente difusa se expressa no projeto de atividades que podem ser denominadas colaborativas, como nos espaços e serviços compartilhados, em atividades produtivas baseadas nos recursos locais mas também articuladas com as amplas redes globais, em iniciativas rela- 
tivas a alimentação natural e saudável, em serviços auto-organizados, em novas formas de intercâmbio e socialização, em sistemas de transportes alternativos, como o bike sharing, car sharing e o carpooling e na organização de redes, que unem de modo direto e ético produtores e consumidores. Para o autor tudo isso é feito através de uma recombinação do existente, sem esperar por uma mudança geral nos sistemas econômicos, institucionais e políticos.

Outra característica comum destes casos é que eles nascem a partir de problemas colocados pela vida cotidiana. Uma terceira particularidade é que as comunidades criativas resultam de uma original combinação de demandas e oportunidades. As demandas são sempre criadas por problemas cotidianos e as oportunidades se manifestam a partir de diferentes combinações de três elementos básicos: a existência das tradições, a possibilidade de utilizar uma série de produtos, serviços e infraestruturas e a existência de condições sociais e políticas favoráveis para o desenvolvimento de uma criatividade difusa.

Ainda segundo Manzini (2008) quando essas comunidades evoluem, tornam-se empreendimentos sociais difusos que, por sua vez, podem se tornar organizações colaborativas.

Um aspecto característico das organizações colaborativas referido por Manzini (2008) é que seu modelo organizacional desafia os modos tradicionais de pensar, indo além das convencionais polaridades dominantes: público/privado, consumidor/produtor, local/global, necessidade/desejo. São iniciativas profundamente enraizadas localmente, mas, ao mesmo tempo, fortemente conectadas com outras semelhantes em escala internacional. São também formas de organização onde, por serem todos participantes ativos, as distinções entre os papéis de produtor e usuário ou consumidor se diluem.

A ideia de que uma projetualidade difusa deve ser cultivada e promovida é um dos temas basilares da obra de Manzini e Jégou (2003). Particularmente, a hipótese dos autores é que se pode, e se deve, operar nesse terreno também com as ferramentas do Design. Portanto, a responsabilidade do Design não é somente aquela de projetar os artefatos, mas também de facilitar o desenvolvimento e a condução das capacidades projetuais difusas e dos contextos que favoreçem a sua implementação. Para os autores a atribuição que os designers podem assumir nesse contexto é aquela de propor cenários de vida e ideias de bem-estar. Os designers contribuem na criação do catálogo de imagens socialmente produzidas com a qual cada indivíduo se confronta na definição de seu próprio projeto de vida (MANZINI; JÉGOU, 2003). Para realizar isso, as ações de design devem partir de uma percepção dos problemas fundamentais. Operar no cotidiano implica iniciar a 
partir de uma observação direta das pessoas em seus contextos, percebendo as suas demandas e os seus comportamentos.

Para Thackara (2008) isso significa que devemos encarar o design como um modo para orientar as coisas, transformando a atribuição do designer de autor de um trabalho acabado para aquele de facilitador no qual o trabalho consiste em ajudar as pessoas para agirem de forma projetual ao interno dos sistemas em que vivem.

Segundo Thackara (2010) uma economia que busca a prosperidade sem sobrecarregar os sistemas naturais e sociais não é algo que se deve criar do nada, ao contrário, em todo o mundo existem centenas de milhares de pequenos projetos que, de um modo ou de outro, são modelos de estilos de vida restaurativos. Para o autor, o problema é que a maior parte desses projetos são pequenos, invisíveis e frágeis. O primeiro passo que se deve fazer na direção desse tipo de comportamento é verificar e contatar as realidades que já trabalham nesse sentido no território.

Nesse contexto, o design pode levantar novos questionamentos, por exemplo, sobre modos alternativos de fornecimento de alimento, água, energia, mobilidade, entre outros. Em seguida, pode promover o encontro entre as pessoas e incitar o diálogo. Para Thackara (2010) os designers são particularmente hábeis em mobilizar as capacidades e assistir as pessoas que se organizam em associações e compartilham recursos.

No entendimento de Thackara (2008), na economia que se espera para o futuro, todos os recursos serão compartilhados: a energia, as matérias-primas, o tempo, as competências, os softwares, o espaço e os alimentos. Uma radical eficiência para o uso dos recursos pressupõe que os produtos sejam considerados como um meio para um determinado fim e não como um fim em si mesmos.

\subsection{A ECOEFICIÊNCIA DE SISTEMA}

Neste campo, a inovação é entendida como um sistema de novas interações entre os atores econômicos e se refere à oferta de produtos e serviços estruturados de acordo com o conceito de ecoeficiência de sistema, isto é, nas situações onde é interessante economicamente para as empresas uma redução em nível sistêmico do consumo dos recursos. Segundo Vezzoli e Manzini (2007) as novidades devem ser promovidas através do estímulo para a criação de novas configurações e novas interações entre os atores que compõem as fases e os ciclos de um determinado sistema produtivo. Isso pode acontecer através da integração entre empresas. Essa integração pode ser do tipo vertical, isto é, 
onde um só ator é, ou se transforma, no responsável por mais fases do ciclo de vida de um produto, ou de tipo horizontal, onde um ator econômico é, ou se transforma, no responsável por mais produtos ou serviços de um determinado sistema produtivo.

Esse conceito se relaciona com o princípio no qual as empresas se organizam para oferecer acesso aos produtos em vez de vendê-los. Vezzoli e Manzini (2007) definem esse princípio como plataformas habilitantes. Essas plataformas são modalidades de oferta de equipamentos ou, em geral, de oportunidades para os clientes obterem de forma mais autônoma os resultados desejados. Nessas plataformas o cliente opera pessoalmente os produtos e ferramentas e, por não possuir tais equipamentos, paga somente pelo seu uso efetivo.

Assim, buscar a inovação pela ecoeficiência de sistema através do design requer novas capacidades. Para Vezzoli e Manzini (2007) significa que o designer deve aprender a projetar conjuntamente produtos e serviços. Em segundo lugar, deve aprender a projetar a configuração dos atores para encontrar soluções inovadoras que conduzam para uma convergência de interesses econômicos, ambientais e sociais. Por fim, deve também aprender a trabalhar num ambiente colaborativo que contenha diferentes empreendedores ou entre empresas, organizações, instituições e, naturalmente, usuários.

\section{CONSIDERAÇÕES FINAIS}

Esta revisão dos princípios da inovação permitiu inferir que a inovação sob a ótica do Design sustentável deve ser entendida como uma força criadora de novos modelos de comportamento que tenham a capacidade de promover, ao mesmo tempo, resultados econômicos para os produtores e modificações significativas no contexto social.

Neste cenário, a tarefa do designer é aquela de propor novos produtos, serviços ou sistemas que se distinguam por suas formas, materiais, processos produtivos, custos, significados e modos de utilização.

Para as empresas e instituições a adoção de práticas orientadas para a inovação pelo Design permite, além dos ganhos econômicos e do incremento da competitividade, a obtenção de benefícios de longo prazo com a vantagem de acompanhar a evolução das necessidades, do comportamento e dos hábitos dos consumidores. Com a progressiva transformação das tecnologias na direção da sexta onda de inovação, a incorporação no Design das estratégias apoiadas nas relações entre a sustentabilidade econômica e a resiliência ambiental torna-se essencial para a obtenção de resultados inovadores. 
A participação dos atores e dos usuários no processo de desenvolvimento de produtos, serviços e infraestruturas é indispensável para a construção de uma economia restaurativa. Considera-se, então, que o atual momento é muito propício para a organização e condução de projetos colaborativos.

As tecnologias devem ser escolhidas e empregadas de forma a tornar as pessoas autônomas, simplificar suas vidas e imprimir uma pegada leve no ambiente. O cotidiano social, os recursos, as competências e as tradições locais representam elementos indispensáveis para a construção do Design sustentável e, consequentemente, tornam-se um campo fértil para novas pesquisas e hipóteses de projeto.

A recorrência de projetos empenhados na busca da inovação pelo Design sustentável pode gerar mudanças sistêmicas, auxiliando em parte no processo de quebra da continuidade dos fatores que geram os desequilíbrios ambiental e social hoje observados.

\section{REFERÊNCIAS}

BONSIEPE, G. Diseño Globalización Autonomía. In: MALDONADO, T.; BONSIEPE, G. 2 textos recientes. La Plata, Argentina: Nodal, 2004 p. 26-75.

CAPELLA, D. Internet è la causa di una rivoluzione estetica. Entrevista com John Thackara. Domus, Milão, n. 826, p. 70-78, maio 2000.

CELASCHI, F. Design come mediatore di saperi. In: GERMAK, C. (Org.). L'uomo al centro del progetto. Turim: Allemandi \& C., 2008.

DAROS, C. Design para a sustentabilidade: oportunidades de inovação a partir dos hábitos de consumo na habitação de interesse social. 2013. 183 f. Dissertação (Mestrado em Design) - PPGDesign/UFPR, Curitiba, 2013.

DE MORAES, D. Metaprojeto como modelo projetual. In: STRATEGIC DESIGN RESEARCH JOURNAL, v. 3, n. 2, p. 62-68, 2010. Disponível em: <http://www. moda.ufc.br/metodologia_projetual/Metaprojeto.pdf >. Acesso em: 3 abr. 2015. FRANZATO, C. $\mathbf{O}$ design estratégico no diálogo entre cultura de projeto e cultura de empresa. In: STRATEGIC DESIGN RESEARCH JOURNAL, v. 3, n. 3, p. 89-96, 2010. Disponível em: <revistas.unisinos.br/index.php/sdrj/article/ view/4791/2045>. Acesso em: 2 abr. 2015.

FREEMAN, C.; PEREZ, C. Structural crises of adjustment: business cycles. In: DOSI, G. (Org.). Technical change and economic theory. Londres: Pinter, 1988. HARGROVES, K.; SMITH, M. The Natural Advantage of Nations: Business Opportunities, Innovation and Governance in the 21st Century. The Natural Edge Project, Earthscan: London, 2005. 
KUHN, T. S. La struttura delle rivoluzioni scientifiche. 5. ed. Tradução de: Adriano Carugo. Turim, Einaudi, 1978.

MANZINI, E. Design para inovação social e sustentabilidade. Comunidades criativas, organizações colaborativas e novas redes projetuais. Rio de Janeiro: E-papers, 2008.

MANZINI, E.; JÉGOU, F. Quotidiano sostenibile. Scenari di vita urbana. Milão: Edizioni Ambiente, 2003.

MARINOVA, D. Global green system of innovation: technological wave or policy? 18 World IMACS/MODSIM Congress. Cairns: Australia, 2009.

OECD. Organisation for Economic Co-operation and Development. Innovation and the environment. 1sted. v. 1. Paris: OECD, 2000, 148 p. v.1.

Technology policy and the environment. Paris: OECD, 2002, $61 \mathrm{p}$.

PENATI, A. Mappe dell'innovazione. Il cambiamento tra tecnica, economia, società. Milão: RCS, 1999.

SCHUMPETER, J. A. Teoria dello sviluppo economico: ricerca sul profitto, il capitale, il credito, l'interesse e il ciclo economico. Tradução de: Lapo Berti. Florença: Sansoni, 1971.

Teoria do Desenvolvimento econômico: uma investigação sobre lucros, capital, crédito, juro e o ciclo econômico. Círculo do Livro: São Paulo, 1999. TAMBORRINI, P. Design sostenibile. Oggetti, sistemi e comportamenti. Milão: Mondadori Electa, 2009.

THACKARA, J. In the bubble. Design per un futuro sostenibile. Tradução de: Niels Betori. Turim: Umberto Allemandi \& C., 2008.

From Doomsday Machine to Clean Growth Economy. In: SUSTAIN/ABILITY FESTIVAL 2010, Treviso, Itália. Treviso Design per un futuro sostenibile, 2010. VERGANTI, R. Design-driven innovation: mudando as regras da competição, a inovação radical do significado de produtos. São Paulo: Canal Certo, 2012.

VERTOVA, G. Joseph Alois Schumpeter come teorico dell'innovazione. Apostila de aula n. 1, lição n. 2. Curso de Graduação em Scienze dell'economia. Disciplina de Economia dell'innovazione, ano acadêmico 2009/2010. Dipartimento di Scienze Economiche, Università degli Studi di Bergamo, Itália, 2009.

VEZZOLI, C.; MANZINI, E. Design per la sostenibilità ambientale. Bolonha: Zanichelli, 2007.

VIEIRA, G. Design e inovação: projeto orientado para o Mercado e centrado no usuário. Revista Convergências, n. 4, 2007. Disponível em: <convergencias.esart. ipcb.pt/artigo/58>. Acesso em: 2 abr. 2015. 
VOSGERAU, D.S.A.R.; ROMANOWSKI, J. P. Estudos de revisão: implicações conceituais e metodológicas. Diálogo Educacional, Curitiba, v. 14, n. 41, p. 165189, jan./abr. 2014.

ZACKIEWICZ, M. et al. Multicriteria analysis for the selection of priorities in the Brazilian program of technology prospection - Prospectar. Innovation (North Sydney), Australia, v. 7, n. 2-3, p. 336-347, 2005. 
André de Souza Lucca é Bacharel em Desenho Industrial e Doutor em Ciências do Design. Entre 2012 e 2013 realizou Pós-doutorado na UFPR colaborando com a equipe do Núcleo de Design e Sustentabilidade. Atualmente é professor adjunto da UFMA e docente do Curso de Ciência e Tecnologia. Efetua pesquisas nas áreas do Design sustentável e do Design para a valorização de produtos, competências e identidades locais. As suas principais publicações são "Indicadores de design para a valorização dos resíduos da construção civil, da indústria sucroalcooleira e da rizicultura no Maranhão", "A etnografia rápida no metaprojeto de design para o território", "Considerações metodológicas para a estruturação de uma abordagem projetual coerente com o Design Sustentável" e "Valorização dos Recursos Locais: Relações entre os Obstáculos da Cadeia de Produtos do Extrativismo e a Gestão do Design".

Carolina Daros é graduada em Tecnologia em Artes Gráficas e Mestre em Design pela UFPR (2011-2013) com a dissertação intitulada: Design para a Sustentabilidade: oportunidades de inovação a partir de hábitos de consumo na habitação de interesse social. Atualmente é doutoranda do PPGDesign da UFPR. Efetua pesquisas nas áreas de Gestão de Design, Cidades Criativas, Economia Criativa, Design e Sustentabilidade, Políticas Públicas (Políticas de Design). As suas principais publicações são "O hábito de lavar roupas"; "Agenda de inovação: estudo exploratório sobre o consumo sustentável de famílias de baixa renda"; "Gestão de Design e Cidades Inteligentes" e "Contribuições do Design para as smart cities".

Recebido em: 27/01/2017

Aceito em: 29/03/2017 